\title{
Hypoxia
}

\section{Stubbs iD}

Department of Anaesthesia, Chris Hani Baragwanath Academic Hospital, University of the Witwatersrand, South Africa Corresponding author, email: melissa.stubbs@gmail.com

Keywords: hypoxia, hypoxaemia, oxygen delivery, oxygen consumption, hypoventilation, shunting, ventilation perfusion mismatch.

Oxygen $\left(\mathrm{O}_{2}\right)$ is the most commonly used drug in medicine and in anaesthesia. ${ }^{1}$ It is vital for all aerobic respiration in humans where it acts as the terminal electron acceptor during oxidative phosphorylation, resulting in the synthesis of adenosine triphosphate (ATP). This in turn supplies energy to all the body's metabolic processes. ${ }^{2}$

Hypoxia is a decrease or failure of oxygenation at a tissue level, ${ }^{3}$ caused by either increased demands, decreased supply or abnormal cellular utilisation. ${ }^{4}$ This therefore results in a decreased amount of oxygen reaching the mitochondria, resulting in anaerobic metabolism, decreased ATP production, increased lactate and ultimately cellular dysfunction and death. ${ }^{3}$

\section{How is oxygen carried in the blood to the cells?}

Oxygen is carried around the body in two ways - the majority is bound to haemoglobin (98.5\%) and the rest is dissolved in plasma $(1.5 \%){ }^{4}$

Haemoglobin $(\mathrm{Hb}) \mathrm{A}$ is an allosteric protein, which consists of four globin chains (two alpha and two beta chains) each containing a haem moiety. ${ }^{5} \mathrm{Hb}$ A makes up over $95 \%$ of all adult haemoglobin. ${ }^{1}$ When oxygen binds to $\mathrm{Hb}$ it results in a conformational change, which then increases the affinity for the binding of other oxygen molecules. This conformational change

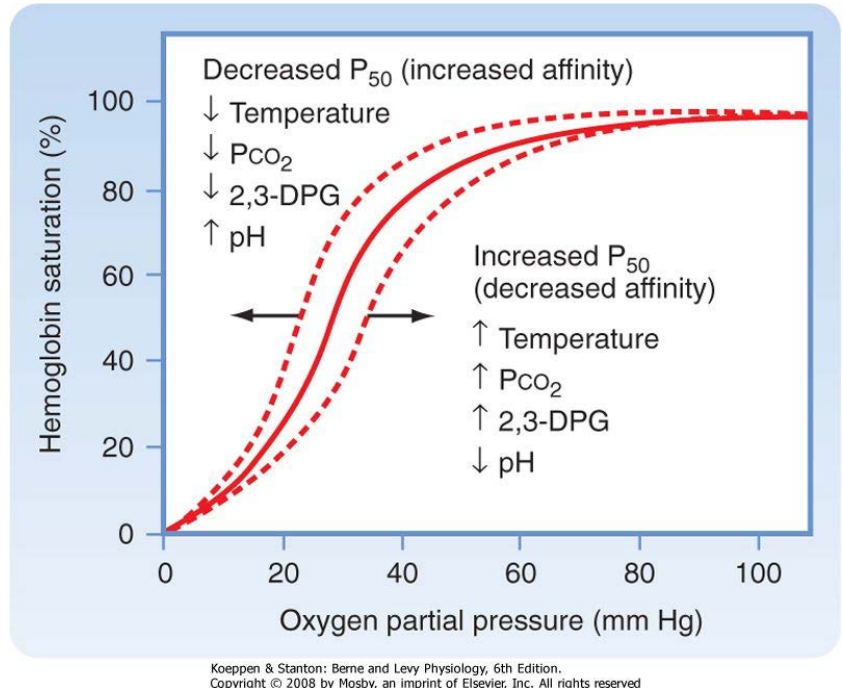

Figure 1: Oxyhaemoglobin dissociation curve ${ }^{6}$ and increased affinity are what results in the typical sigmoidal shape of the oxyhaemoglobin dissociation curve. ${ }^{5}$

The relaxed $(\mathrm{R})$ state of $\mathrm{Hb}$ has a high affinity for oxygen while the taut/tight $(T)$ form has a low oxygen affinity. Other factors which affect affinity are shown in Figure 1.5

Oxygen content is the sum of oxygen in each $100 \mathrm{ml}$ of blood both bound to haemoglobin and dissolved in plasma. ${ }^{7}$

Arterial oxygen content $\left(\mathrm{CaO}_{2}\right)=$ bound oxygen + dissolved oxygen

$\mathrm{CaO}_{2}=\left(1.34 \times \mathrm{Hb} \times \mathrm{SaO}_{2}\right)+\left(0.003 \times \mathrm{PaO}_{2}\right)$

1.34 = Hüfners constant, which reflects the amount of oxygen in millilitres that each $1 \mathrm{~g}$ of $\mathrm{Hb}$ can carry ${ }^{5}$

$0.003=$ solubility coefficient of oxygen at room temperature

$\mathrm{SaO}_{2}=$ percentage arterial $\mathrm{O}_{2}$ saturation in blood

$\mathrm{PaO}_{2}=$ partial pressure of oxygen in arterial blood

Which factors affect oxygen delivery and consumption?

Oxygen delivery $\left(\mathbf{D O}_{2}\right)$ is the product of cardiac output (CO) and arterial oxygen content: ${ }^{7}$

$\mathrm{DO}_{2}=\mathrm{CO} \times \mathrm{CaO}_{2}$

Alterations in delivery or any factors contributing to poor delivery will result in hypoxia.

Oxygen consumption $\left(\mathrm{VO}_{2}\right)$ is the amount of oxygen consumed by tissues per minute and can be calculated directly by analysing the respiratory gases or indirectly using Fick's principle. ${ }^{4}$

$\mathrm{VO}_{2}=\mathrm{CO} \times\left(\mathrm{CaO}_{2}-\mathrm{CvO} \mathrm{O}_{2}\right.$

$\mathrm{CvO}_{2}=$ venous $\mathrm{O}_{2}$ content of blood

The consumption will depend on the metabolic demand of cells and will obviously need to increase during exercise, trauma, sepsis, pain, etc. ${ }^{5}$

The oxygen extraction ratio $\left(\mathrm{O}_{2} \mathrm{ER}\right)$ is the ratio of $\mathrm{VO}_{2}$ to $\mathrm{DO}_{2}$ and represents the fraction of oxygen delivered to and taken up 
by the tissues. It is usually $0.2-0.3$ in most tissues but increases to 0.6 in the heart where more $\mathrm{O}_{2}$ is utilised. ${ }^{4}$

$\mathrm{O}_{2} E R=\frac{\mathrm{VO}_{2}}{\mathrm{DO}_{2}}$

As mentioned, hypoxia can occur when there is either a decrease in $\mathrm{O}_{2}$ delivery or a decrease in the ability of the cells to utilise $\mathrm{O}_{2}$. It can also result when the consumption of $\mathrm{O}_{2}$ exceeds the ability to deliver. ${ }^{2}$

\section{What are the causes of hypoxia?}

'Hypoxia' and 'hypoxaemia' are often interchangeably used, but are not the same condition:

- Hypoxia is a decrease or failure of oxygenation at tissue level, therefore resulting in a decreased amount of $\mathrm{O}_{2}$ reaching the mitochondria.

- Hypoxaemia is an abnormally low $\mathrm{O}_{2}$ tension of arterial blood $\left(\mathrm{PaO}_{2}\right)$.

There are four types of hypoxia: ${ }^{3}$

- Hypoxic hypoxia occurs when there is a failure in the transfer of $\mathrm{O}_{2}$ from the environment to the pulmonary capillaries. ${ }^{2}$ This results in an abnormally low $\mathrm{PaO}_{2}$. Causes are discussed below.

- Anaemic hypoxia is a decreased $\mathrm{O}_{2}$ content in the arterial blood related to $\mathrm{Hb}$ concentration. $\mathrm{PaO}_{2}$ is usually normal.

- Stagnant hypoxia is an inadequate delivery of oxygenated blood to the tissue. $\mathrm{PaO}_{2}$ is usually normal but delivery is compromised, e.g. due to low cardiac output.

- Histotoxic hypoxia involves impaired uptake or utilisation of $\mathrm{O}_{2}$ by the tissue. This can be as a result of poisons, e.g. cyanide. ${ }^{8}$

Hypoxic hypoxia is the most common type and may be due to: ${ }^{9}$

1. Low fraction of inspired oxygen

2. Hypoventilation

3. Shunting

4. Diffusion limitation

5. Ventilation/perfusion mismatch (V/Q)

Types 3, 4 and 5 can also be classified under pulmonary hypoxia. ${ }^{9}$

The five types of hypoxic hypoxia

1. Low fraction of inspired oxygen $\left(\mathrm{FiO}_{2}\right)$. The arterial oxygen tension (although slightly lower) is directly related to alveolar oxygen tension. ${ }^{8}$

The alveolar gas equation is used to calculate the alveolar oxygen tension $\left(\mathrm{PAO}_{2}\right)$. $^{3}$

$\mathrm{PAO}_{2}=\mathrm{F}_{i} \mathrm{O}_{2}\left(\mathrm{P}_{a t m}-\mathrm{P}_{\mathrm{H} 2 \mathrm{O}}\right)-\frac{\mathrm{PaCO}_{2}}{\mathrm{R}}$

$P_{a t m}=$ the atmospheric pressure, which at sea level is $760 \mathrm{mmHg}$ $\mathrm{P}_{\mathrm{H} 2 \mathrm{O}}=$ the saturated vapor pressure of water at body temperature $(47 \mathrm{mmHg})$

$\mathrm{PaCO}_{2}=$ the arterial partial pressure of $\mathrm{CO}_{2}$

$\mathrm{R}=0.8$ which is the respiratory exchange ratio under resting conditions.
A low $\mathrm{FiO}_{2}$ can be due to high altitude (decreased $\mathrm{P}_{\mathrm{atm}}$ ), asphyxia, and even during anaesthesia with a failure of the oxygen delivery systems or an excessive inspired concentration of nitrous oxide. ${ }^{3}$

2. Hypoventilation. This may occur due to a low respiratory rate and/or decreased tidal volume with reduced minute ventilation. Reduced minute ventilation results in an increased alveolar and arterial $\mathrm{PCO}_{2}$ and a decreased $\mathrm{P}_{\mathrm{A}} \mathrm{O}_{2}{ }^{8}$

Some causes of alveolar hypoventilation include: 9

- Underlying lung and airway pathology

- Obstructive airway diseases

- Neuromuscular diseases (such as myasthenia gravis or Guillain-Barré syndrome)

- Deformities of the chest or spine

- Respiratory depression from sedation or analgesia

3. Shunting refers to venous blood bypassing oxygenation in the pulmonary capillaries and reaching the left side of the heart without participating in ventilation, therefore it is not involved in oxygenation or $\mathrm{CO}_{2}$ removal. ${ }^{2}$ There are two types of shunts - anatomic and physiologic. ${ }^{8}$

The anatomic shunt occurs when blood bypasses the lung through an anatomic conduit from the right to left ventricle such as occurs with a ventricular septal defect. ${ }^{9}$ It can also occur in normal healthy subjects when the thebesian veins from the myocardium empty directly into the left atrium and also where bronchial veins empty directly into the pulmonary veins, and therefore bypass gas exchange in the lungs. ${ }^{10}$

A physiologic shunt occurs when there is pathology in the lung parenchyma that results in blood circulating through the pulmonary vessels without undergoing ventilation in that affected region of the lung. These pathological conditions include atelectasis, pulmonary oedema, pulmonary embolism, pneumonia, aspiration, and pneumothorax. ${ }^{8}$

This shunted poorly oxygenated blood then mixes with the non-shunted oxygenated blood and reduces the arterial oxygen content resulting in hypoxia. ${ }^{2}$

The shunt can be quantified using the shunt equation: ${ }^{8}$

$\frac{Q_{s}}{Q_{t}}=\frac{\mathrm{CcO}_{2}-\mathrm{CaO}_{2}}{\mathrm{CcO}_{2}-\mathrm{CvO}_{2}}$

$\mathrm{Q}_{\mathrm{s}}=$ pulmonary shunt

$\mathrm{Q}_{\mathrm{t}}=$ cardiac output ( $\mathrm{ml} / \mathrm{min}$ )

$\mathrm{CcO}_{2}=$ end pulmonary capillary $\mathrm{O}_{2}$ content

$\mathrm{CaO}_{2}=$ arterial $\mathrm{O}_{2}$ content

$\mathrm{CvO}_{2}=$ mixed venous $\mathrm{O}_{2}$ content

4. Diffusion limitation or impairment occurs when the alveolar capillary membranes thicken. This thickening occurs in interstitial lung diseases such as pulmonary fibrosis, ARDS, pulmonary oedema, pneumonitis and connective tissue disorders. ${ }^{10}$

Oxygen within the lung normally diffuses down the concentration gradient from the alveoli to the pulmonary capillaries. 
Early in the disease process impaired diffusion is offset by improved transit time of the pulmonary capillary system. As the disease progresses, the severity of the diffusion abnormality outdoes the transit time and hypoxemia ensues. ${ }^{10}$

Diffusion is measured using Fick's Law: ${ }^{2}$

$\mathrm{JO}_{2}=A \times D\left(\frac{\mathrm{PAO}_{2}-\mathrm{PvO}}{\mathrm{T}}\right)$

$\mathrm{JO}_{2}=$ rate of oxygen diffusion

$A=$ surface area

$\mathrm{T}=$ thickness of membrane

$\mathrm{D}=$ diffusion constant

$\left(\mathrm{PAO}_{2}-\mathrm{PvO}_{2}\right)=$ alveolar oxygen pressure gradient

5.V/Q mismatch. The V/Q ratio shows the relationship between ventilation (oxygen that reaches the alveoli) and perfusion (blood that passes by the alveoli). The presence of a V/Q mismatch shows that not all the alveoli are equally perfused and equally ventilated. ${ }^{2}$ The ideal $\mathrm{V} / \mathrm{Q}$ ratio is 1 , but in a healthy individual, the V/Q actually equals approximately 0.8 . While ventilation and perfusion both increase going from the apex to the base, perfusion increases more, thereby lowering the $\mathrm{V} / \mathrm{Q}$ ratio at the base. The ratio varies according to the position of the patient. In the upright position, V/Q equals 1 only in the middle lung zones. At the apex of the lung, ventilation is greater than perfusion (V/Q $>1)$ and at the base, perfusion is greater than ventilation $(\mathrm{V} / \mathrm{Q}<1) .^{10}$

A low V/Q ratio is found in a number of pathological conditions, including chronic obstructive pulmonary disease (COPD), asthma, and bronchitis. The decreased V/Q in these conditions is due to the reduced ventilation that takes place. ${ }^{9}$ In contrast, an embolism causes occlusion of the vessels. This occlusion causes a high V/Q ratio as there are now areas of dead space ventilation, meaning that areas that are being ventilated are now poorly perfused due to the occlusion. The ventilation is essentially wasted, as it is unable to oxygenate any blood or eliminate $\mathrm{CO}_{2} \cdot{ }^{10}$

During general anaesthesia, the functional residual capacity decreases due to a change in the balance between outward forces, respiratory muscle tone, and inward forces such as lung elastic recoil. The loss of respiratory muscle tone causes a

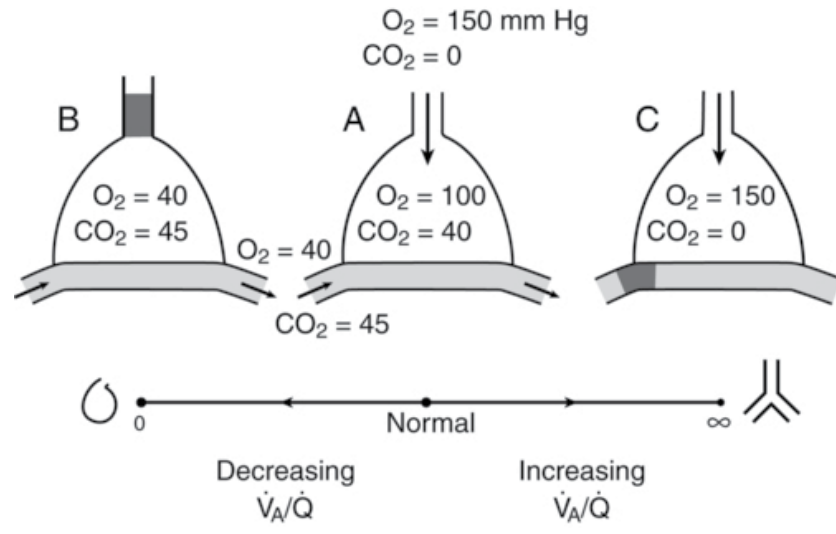

Figure 2: Ventilation/perfusion ratios and the effects on $\mathrm{PO}_{2}$ and $\mathrm{PCO}_{2}{ }^{11}$

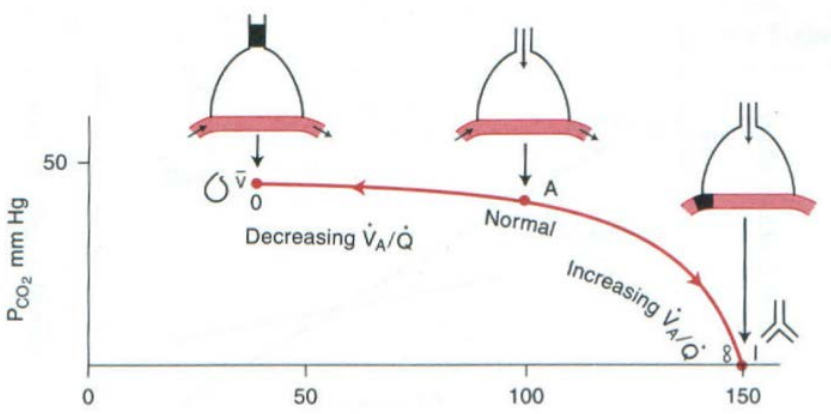

Figure 3: Ventilation/perfusion ratio line ${ }^{11}$

decrease in lung compliance resulting in atelectasis; this then contributes to the shunt effect. There is also a redistribution of inspired alveolar gas from dependent to nondependent regions of the lungs, some of which may not be perfused and will therefore lead to either a V/Q mismatch or dead space ventilation. ${ }^{11}$

The V/Q mismatch is estimated by measuring the physiological dead space: ${ }^{8}$

$\frac{V_{d}}{V_{t}}=\frac{\mathrm{PaCO}_{2}-\mathrm{PeCo}_{2}}{\mathrm{PaCO}_{2}}$

$\mathrm{V}_{\mathrm{d}}=$ alveolar dead space

$\mathrm{V}_{\mathrm{t}}=$ tidal volume

$\mathrm{PaCO}_{2}=$ partial pressure of carbon dioxide in the arterial blood $\mathrm{PeCO}_{2}=$ partial pressure of expired carbon dioxide

Normal Vd/Vt ratio is $0.2-0.3$ and can increase to 0.5 in patients with a V/Q mismatch. ${ }^{8}$

Anatomical dead space is that part of the airways (such as the mouth and trachea to the bronchioles) which conducts gas to the alveoli, but no gas exchange can take place in these spaces. Anatomic dead space is usually around $1 / 3$ of tidal volume, therefore about $150 \mathrm{ml}$.

Physiological dead space in addition to this can be influenced by numerous factors such as respiratory cycle, positioning and V/Q mismatch as mentioned above. ${ }^{11}$

\section{How to differentiate causes of hypoxia using the} alveolar-arterial gradient?

The alveolar-arterial (A-a) $\mathrm{PaO}_{2}$ gradient is a measure of the difference between the alveolar concentration $(A)$ of oxygen and the arterial (a) concentration of oxygen. It is useful in diagnosing the cause of hypoxia. $\mathrm{PAO}_{2}$ is always higher than $\mathrm{PaO}_{2} \cdot{ }^{12}$

For example, in areas of high altitude, the arterial oxygen $\mathrm{PaO}_{2}$ is low but only because the alveolar oxygen $\left(\mathrm{PAO}_{2}\right)$ is also low therefore the A-a gradient will be normal. However, in cases with ventilation perfusion mismatch, such as pulmonary embolism or right-to-left shunt, oxygen cannot be effectively transferred from the alveoli to the blood. This will then result in an elevated A-a gradient. ${ }^{10}$

\section{A-a gradient $=\mathrm{PAO}_{2}-\mathrm{PaO}_{2}$}

Normal $10-12 \mathrm{mmHg}^{3}$

Abnormal $>20$ 
A-a gradient will change based on age and the estimated normal A-a gradient $=($ Age +10$) / 4$

Table I: Summary table - differentiating the causes of hypoxia ${ }^{12}$

\begin{tabular}{lcc} 
Cause & $\mathbf{O}_{\mathbf{2}}$ response & A-a gradient \\
\hline $\begin{array}{l}\text { 1. Decreased/low inspired } \mathrm{O}_{2} \\
\begin{array}{l}\text { 2. Inadequate ventilation/ } \\
\text { hypoventilation }\end{array}\end{array}$ & Yes & Normal \\
$\begin{array}{l}\text { 3. Shunting } \\
\text { 4. Diffusion limitation }\end{array}$ & No & Elevated \\
$\begin{array}{l}\text { 5. Ventilation/perfusion } \\
\text { mismatch }(\mathrm{V} / \mathrm{Q})\end{array}$ & Yes & Elevated \\
\hline
\end{tabular}

\section{Conflict of interest}

The author declares no conflict of interest.

\section{Funding source}

None.

\section{ORCID}

M Stubbs (iD https://orcid.org/0000-0002-7935-7955

\section{References}

1. Dunn J-O, Nythen M, Grocott M. Physiology of oxygen transport. BJA Educ. 2016;16(10):341-8. https://doi.org/10.1093/bjaed/mkw012.

2. Nam F. FCA Part 1 Refresher - Hypoxia. University of the Witwatersrand; 2011.

3. Radford H. FCA Part 1 Refresher - Hypoxia in the perioperative setting. University of the Witwatersrand; 2015.

4. McLellan S, Walsh T. Oxygen delivery and haemoglobin. BJA Educ. 2004;4(4):1236. https://doi.org/10.1093/bjaceaccp/mkh033.

5. Morford M. FCA Part 1 Refresher - DO2, VO2 and the oxyhaemoglobin curve. University of the Witwatersrand; 2016.

6. Koeppen B, Stanton B. In: Berne and Levy Physiology. 6th ed. Philadelphia: Mosby; 2010. p. 462.

7. Anaesthesia UK. Oxygen content of blood. EPub 2005 Aug 20. Accessed 20 March 2020. Available from: https://www.frca.co.uk/article. aspx?articleid=100344.

8. Lines D. FCA Part 1 Refresher - Hypoxaemia. University of the Witwatersrand 2012.

9. Bhutta B, Faysal A, Ilya B. Anoxia (Hypoxic Hypoxia). In: StatPearls [Internet] StatPearls Publishing; 2020. Available from: https://www.ncbi.nlm.nih.gov/ books/NBK482316/.

10. Sarkar M, Niranjan N, Banyal P. Mechanisms of hypoxemia. Lung India. 2017;34(1):47-60. https://doi.org/10.4103/0970-2113.197116.

11. West JB. In: Respiratory physiology - The essentials. 10th ed. Philadelphia: Wolters Kluwer; 2015. p. 20-24, 72-3.

12. Hantzidiamantis $P$, Amaro E. Physiology, alveolar to arterial oxygen gradient. StatPearls Publishing; 2019. Available from: https://www.ncbi.nlm.nih.gov/ books/NBK545153/. 